\title{
Assessing Topsoil Movement in Rotary Harrowing Process by RFID (Radio-Frequency Identification) Technique
}

\author{
Ahmed Kayad ${ }^{1,2, *(\mathbb{D})}$, Riccardo Rainato ${ }^{1}\left(\mathbb{D}\right.$, Lorenzo Picco ${ }^{1,3,4} \mathbb{D}^{\mathbb{D}}$, Luigi Sartori ${ }^{1} \mathbb{D}$ and \\ Francesco Marinello ${ }^{1}$ (D) \\ 1 Department TESAF, University of Padova, viale dell'Università, 16, I-35020 Legnaro (PD), Italy \\ 2 Agricultural Engineering Research Institute (AEnRI), Agricultural Research Centre, Giza 12619, Egypt \\ 3 Faculty of Engineering, Universidad Austral de Chile, Campus Miraflores, Valdivia 5090000, Chile \\ 4 Universidad Austral de Chile, RINA-Natural and Anthropogenic Risks Research Center, \\ Campus Miraflores, Valdivia 5090000, Chile \\ * Correspondence: ahmed.kayad@phd.unipd.it; Tel.: +39-049-827-2722
}

Received: 1 July 2019; Accepted: 15 August 2019; Published: 19 August 2019

\begin{abstract}
Harrowing is a process that reduces the size of soil clods and prepares the field for seeding. Rotary harrows are a common piece of equipment in North Italy that consists of teeth rotating around a vertical axis with a processing depth of $5-15 \mathrm{~cm}$. In this study, the topsoil movement in terms of distance and direction were estimated at different rotary harrow working conditions. A total of eight tests was performed using two forward speeds of 1 and $3 \mathrm{~km} / \mathrm{h}$, two working depths of 6 and $10 \mathrm{~cm}$ and two levelling bar positions of 0 and $10 \mathrm{~cm}$ from the ground. In order to simulate and follow topsoil movement, Radio-Frequency Identification (RFID) tags were inserted into cork stoppers and distributed in a regular pattern over the soil. Tags were distributed in six lines along the working width and repeated in three rows for each test: a total number of 144 tags was tracked. Results showed that there were no significant differences between the performed tests, on the other hand the reported tests highlight the effectiveness of the RFID monitoring approach.
\end{abstract}

Keywords: rotary harrow; secondary tillage; soil erosion; RFID

\section{Introduction}

Soil tillage is an agronomic practice that effects on both soil and crop properties. The main objective for tillage operations is to improve the soil environment for seed germination and, subsequently, improve crop yield [1-3]. There are several kinds of tillage methods and tools such as conventional tillage, which is commonly divided into primary and secondary tillage. In primary tillage, moldboard or chisel plows make the major part of the tillage operation. Meanwhile, soil surface after primary tillage still needs further operation in order to smooth and reduce clods size. Therefore, secondary tillage operation by rotary harrow is used for preparing suitable seedbed [4].

Tillage operations have a great impact on topsoil in terms of aggregate size and crop residue cover, which plays an important role in sustainable agriculture. A minimum amount of residue is needed to protect soil erosion, reduce greenhouse gas emissions and maintain soil carbon level [5-8]. The impact of tillage operations on topsoil depend on tillage operational depth and speed, soil characteristics, initial amount of residues, and type of used equipment $[9,10]$.

The contribution of harrowing in soil erosion could be realized from weed dispersal studies [4]. Soil movement by tillage operations was investigated through different instruments [11] and different approaches [12,13]. Researchers used different techniques to monitor soil movement such as plastic 
beads [14], granite rocks [13], or aluminum cubes [4]. It is in the authors' opinion that Radio-Frequency Identification (RFID) systems can be successfully applied for this scope.

The RFID is a system that transmits the identity of an object using radio waves and consists of RFID tags and RFID readers. RFID tags are small electronic devices attached to objects and RFID reader is an antenna that identifies the tags [15]. The passive tags have no power source and discovered by antenna within $0.5-1.0 \mathrm{~m}$ radius while other tags may include batteries to be detected at higher distances $[16,17]$. In recent years, due to relatively low costs, many applications have been developed based on RFID such as location identification for many shipping and postal services, security purposes in shops and companies, retailers and supply chain for confirming that products on shelf, payment systems for payments at drive-through windows, livestock and agricultural production monitoring [18-21]. With reference to the soil, some recent advancements have been reported, mainly dealing with the assessment of erosion, landslide displacement monitoring, or sediment mobility [22-25], while the authors are not aware of RFID applications in relation to soil tillage practices.

The main objective of this study is to assess the movements of topsoil layer after the application of a tillage operation such as rotary harrowing. In addition, the study highlights how RFID technology can be effectively applied in order to simulate crop residues or even soil clods for tillage experiments as more robust technique especially in open field trials (Supplementary Materials S1).

\section{Materials and Methods}

This study was conducted at a 5 ha field in Agripolis experimental field (University of Padova, Italy). The soil can be defined, according to the United State Department of Agriculture (USDA), as loamy and containing $46 \%$ sand, $30 \%$ silt, and $24 \%$ clay. Primary tillage was applied at the end of the winter season and followed by a harrowing process as secondary tillage on May 2018 in order to prepare the soil for soybean sowing. It is worth noting how most of crop residues are buried after primary tillage, especially in the case of mouldboard ploughing. Such conditions were helpful in order to maximize the understanding of implemented RFID tags dynamics.

A rotary harrow with two horizontal rollers from Alpergo Co., Lonigo, VI, Italy (Model: Rotodent DP) was used to perform the harrowing process. The implement consisted of a series of 20 pairs of tines (indicated by $A$ in Figure 1) which rotate about a vertical axis in order to produce soil disturbance over a working width of $5 \mathrm{~m}$. The working volume is limited on the back by a levelling bar ( $B$ in Figure 1): its height relatively to the ground can be adjusted in order to limit the flow of clods through the machine and allow a better control on aggregates dimensions. The levelling bar thus allows the soil to be hold for a certain time (from a few tenths up to a few seconds depending on its relative position) within the shell where the tines operate, allowing aggregates mixing and reduction. Two horizontal cage rollers ( $C$ in Figure 1 ) were positioned on the back end of the rotary harrow to allow soil compaction and levelling. The implement was driven by a $160 \mathrm{hp}$ tractor through the three-point hitch and Power Take Off (PTO) shaft at $1000 \mathrm{rpm}$.

A RFID package from Oregon RFID Co., Portland, OR, USA was implemented in this work. This package consists of RFID reader and passive tags. Tags are in a cylindrical shape with $3.65 \mathrm{~mm}$ diameter and $23 \mathrm{~mm}$ length. Being small in dimensions and weight (less than 1 gram) allows their integration into bigger envelopes. In fact, in order to simulate topsoil components such as crop residues and soil clods, a cork stopper was drilled laterally and one RFID tag inserted inside each stopper then closed by glue. Cork stoppers were chosen, due to their wide availability, durability, and high similarity (in terms of shape, size, and density) specially with crop residues such as dry corn stems or corncob. Furthermore, they allow to damp the effects of rotary harrow tools, minimizing the eventuality of damages to the delicate RFID tags. Each tag (and thus each cork stopper) had an identification number which allowed individual monitoring. Additionally, cork trackers were painted with shining fluorescent color and tag identification number in order to facilitate recognition after the harrowing process (Figure 2). 

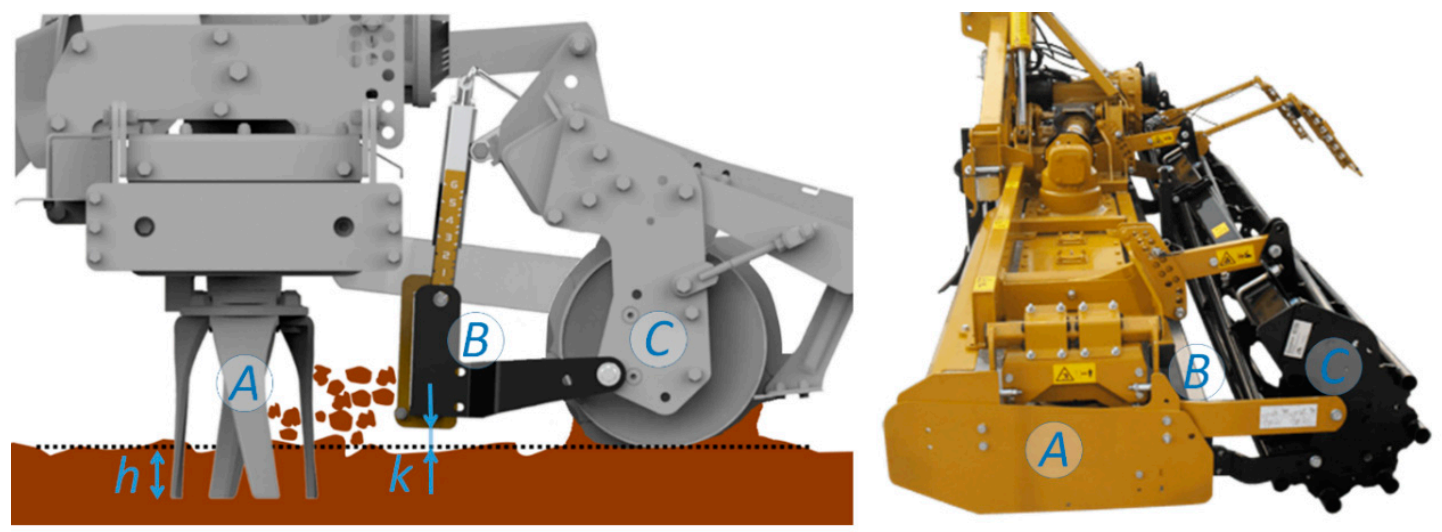

Figure 1. On the left schematic view and on the right a picture of the implemented harrowing machine, with indication of the working depth $h$ of the rotary tines (A) and of the height $k$ of the levelling bar (B) closing the back part of the working volume; Soil is eventually levelled by a couple of cage rollers (C).
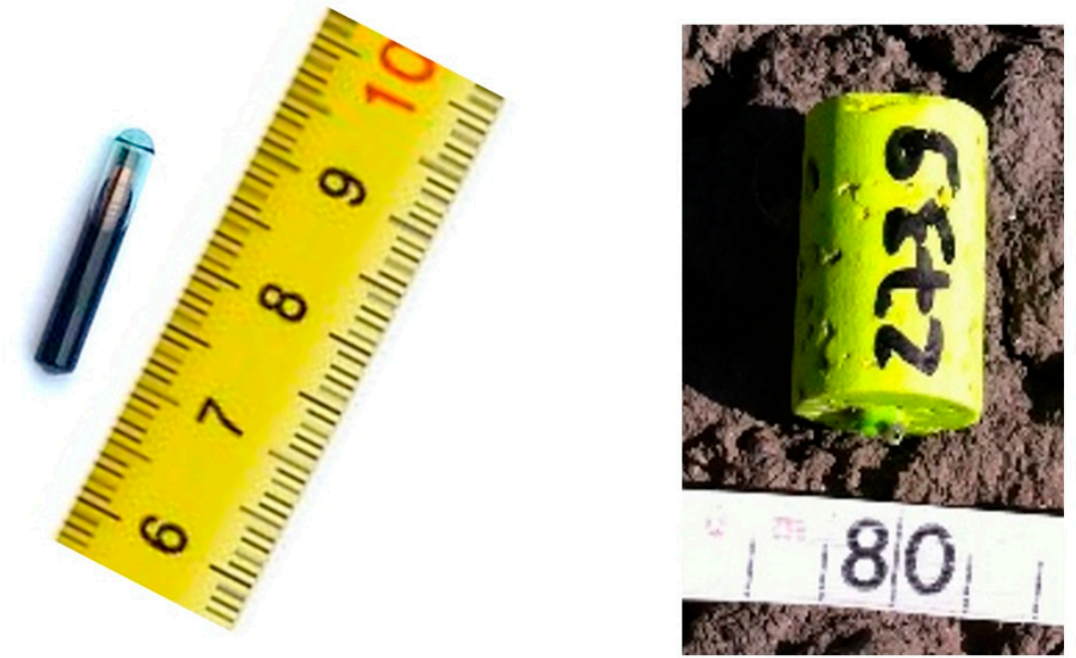

Figure 2. On the left a picture if the RFID tag, and on the right a cork stopper with RFID inside, painted and numbered.

The experimental field was divided into two lateral strips $(5 \mathrm{~m} \times 80 \mathrm{~m})$ and each strip consisted of four different working conditions, as summarized in Table 1 and depicted in Figure 3 . The different applied working conditions were as follows: two forward speeds of 1 and $3 \mathrm{~km} / \mathrm{h}$, two working depths (namely $h$ in Figure 1) of 6 and $10 \mathrm{~cm}$, and two levelling bar positions (namely $k$ in Figure 1) of 0 (i.e., at ground level) and $10 \mathrm{~cm}$ (i.e., lifted up from the soil). Eight working conditions were investigated by using the RFID trackers. In each treatment, 18 trackers were distributed in six lines and three rows. The distance between rows was $1 \mathrm{~m}$ while the distance between lines were 40, 80, $220,280,420$, and $460 \mathrm{~cm}$ starting from one of the harrow sides in order to maintain a symmetric measurement between the two horizontal rollers (Figure 3). The three rows of trackers act as replicates for each treatment.

Trackers' positions were recorded in conjunction with their identification number and tested with the RFID antenna before applying the experimental treatments. After performing each treatment, the position of each tracker was recorded in order to investigate its movement in terms of distance, depth, and direction. At the start of each treatment, two stick markers were fixed to act as a datum for trackers position recognition (Figure 3 C). 
Table 1. Experimental conditions.

\begin{tabular}{ccccc}
\hline Acronym & $\begin{array}{c}\text { Forward Speed } \\
(\mathbf{k m} / \mathbf{h})\end{array}$ & $\begin{array}{c}\text { Working Depth } \\
\mathbf{( c m )}\end{array}$ & $\begin{array}{c}\text { Levelling Bar } \\
\text { Position } \mathbf{( c m )}\end{array}$ & Reference \\
\hline \multirow{2}{*}{ V1D10 } & 1 & 10 & 0 & Figure 3B a \\
& 1 & 10 & 10 & Figure 3B e \\
V3D10 & 3 & 10 & 0 & Figure 3B b \\
& 3 & 10 & 10 & Figure 3B f \\
V1D6 & 1 & 6 & 0 & Figure 3B c \\
& 1 & 6 & 10 & Figure 3B g \\
V3D6 & 3 & 6 & 0 & Figure 3B d \\
& 3 & 6 & 10 & Figure 3B h \\
\hline
\end{tabular}
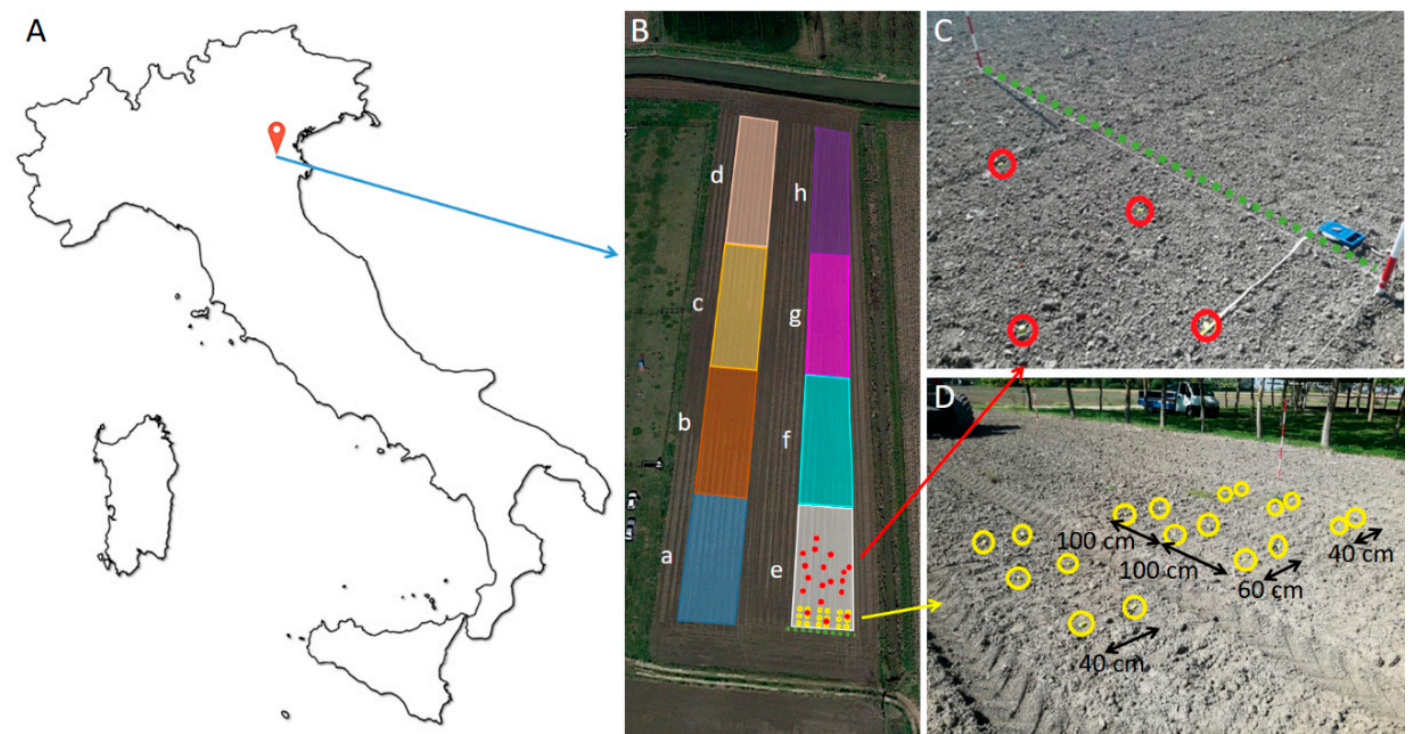

Figure 3. (A) - Geographical localization of the experimental site in Italy. (B) -Experimental area with representation of the experimental design. (C)—Some of the tags after tillage operation. (D)-Trackers distribution on undisturbed soil, before harrowing process.

\section{Results and Discussion}

A total number of 144 trackers were tracked after applying eight different treatments of rotary harrowing. Trackers were localized by naked eye in the case of surface positions, conversely buried trackers (more than eighty) were localized taking advantage of the RFID reader. During the experiments, only two of the trackers were lost: in such cases they were not revealed by the RFID reader most probably due to some breakage occurred during harrowing operation. Hence, the overall recovery rate was $98.6 \%$. Results showed that there was a clear movement in the machine direction with an average value of $2.3 \mathrm{~m}$, but exceeding $5 \mathrm{~m}$ in different situations. On the other hand, the lateral movement was limited to an average of $0.2 \mathrm{~m}$. The average movements for applied treatments are shown in Figure 4 .

The major direction for trackers movement was in the machine direction. The major factor that effected on movement distance was noticed from the levelling bar. The average movement were 2 and $0.8 \mathrm{~m}$ at bar level of 0 and $10 \mathrm{~cm}$, respectively. Also, many trackers moved more than $5 \mathrm{~m}$ in the machine direction with the bar at ground level, compared to less than $2.5 \mathrm{~m}$ in the case of lifted up bar. This is ascribable to the fact that when the levelling bar is down, the amount of soil kept within the chamber between tines and levelling bar itself increases. Concurrently, there is an increase in the amount of time soil remains within such chamber: aggregates exit only after their size has been sufficiently reduced to pass under the levelling bar. Such phenomenon results in a longer distance done by clods or residues (and thus also by the RFID tags) and in a higher chance of burial effects. Moreover, as tines are rotating, there is a probability of hitting the cork trackers which may throw trackers to a 
forward or backward direction. In case of backward thrown, the levelling bar prevents trackers from moving beyond that barrier. In contrary, there is no limit for the forward thrown where there is no barrier and the rugged material of cork trackers may explain the long forward displacement in some cases. Figure 5 illustrates the forward movement at different rotary harrow working conditions.
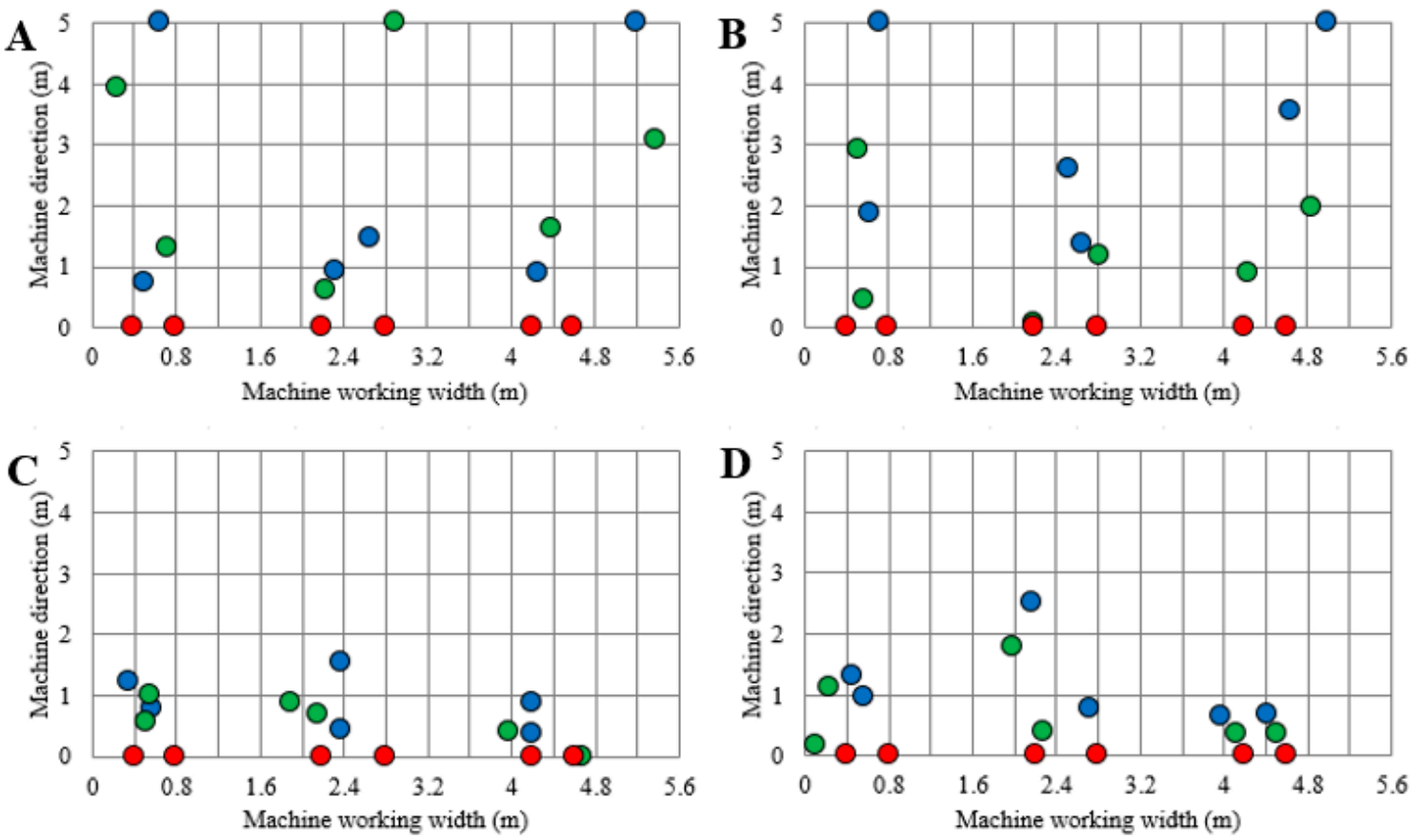

- Datum $\bullet 1 \mathrm{~km} / \mathrm{hr} \bullet 3 \mathrm{~km} / \mathrm{hr}$

Figure 4. Average trackers movement at different rotary harrow working conditions where: (A) at level bar of zero and depth of $6 \mathrm{~cm},($ B) at level bar of zero and depth of $10 \mathrm{~cm},(\mathbf{C})$ at level bar of $10 \mathrm{~cm}$ and depth of $6 \mathrm{~cm}$, and (D) at level bar of $10 \mathrm{~cm}$ and depth of $10 \mathrm{~cm}$.
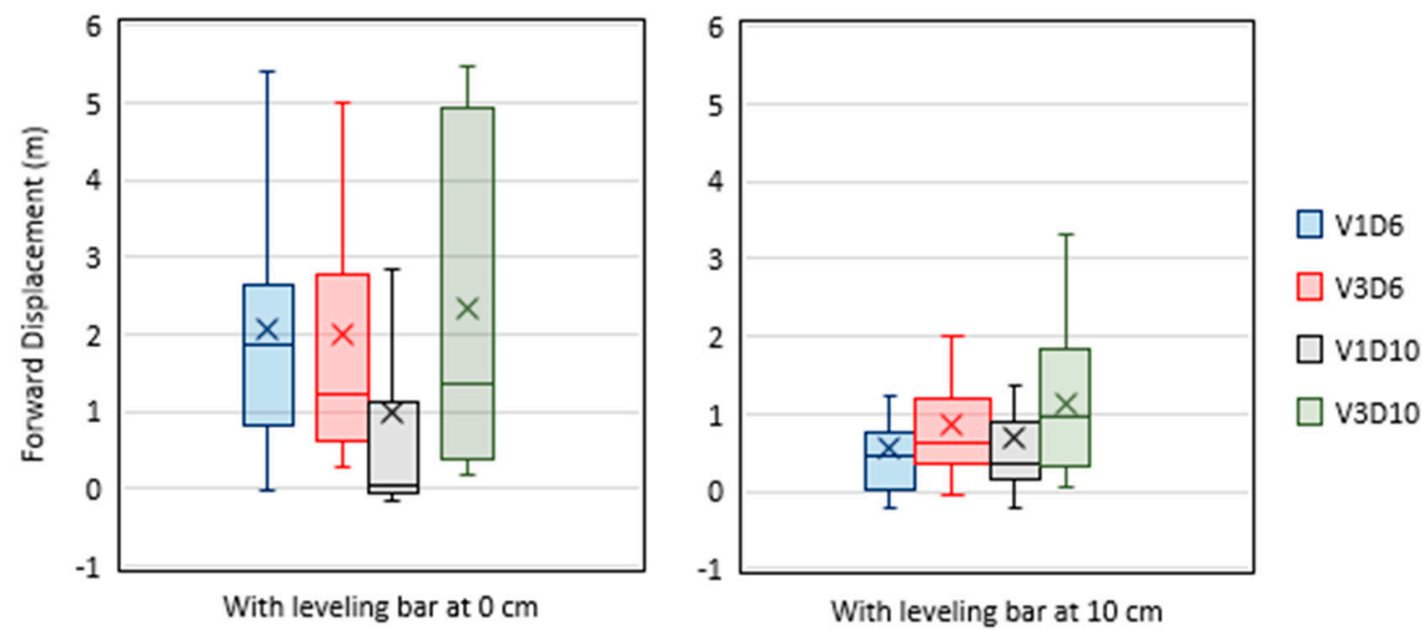

Figure 5. Average trackers forward movement at different working conditions where V1 and V3 refer to forward speed of 1 and $3 \mathrm{~km} / \mathrm{h}$. Also, D6 and D10 refer to working depth of 0.06 and $0.1 \mathrm{~m}$.

Shifts in lateral direction were limited to $0.03 \mathrm{~m}$ left on average, with a standard deviation as high as $0.40 \mathrm{~m}$. This is in agreement with the rotary harrow symmetric construction, where clockwise and anticlockwise rotating tine pairs are alternated: such working mode allows avoidance of soil piling phenomena, as confirmed by RFID distribution. In this case, the levelling bar position plays only a marginal role statistically irrelevant: $0.12 \mathrm{~m}$ right lateral displacement in the case of bar at ground level 
and $0.20 \mathrm{~m}$ left shift in the case of lifted up position. A slightly different situation is highlighted in the case of analyses related to tags depth. In fact, lower position of the levelling bar caused an average increase on burial phenomenon from $-0.8 \mathrm{~cm}$ to $-1.5 \mathrm{~cm}$ on average. Such apparently low values (compared to the working depth) are most probably ascribable to some kind of floating phenomenon the cork stoppers underwent due to their density, sensibly lower than soil clods density, but comparable to crop residues one. Figures 6 and 7, illustrates the lateral movement and burial depth at different rotary harrow working conditions.
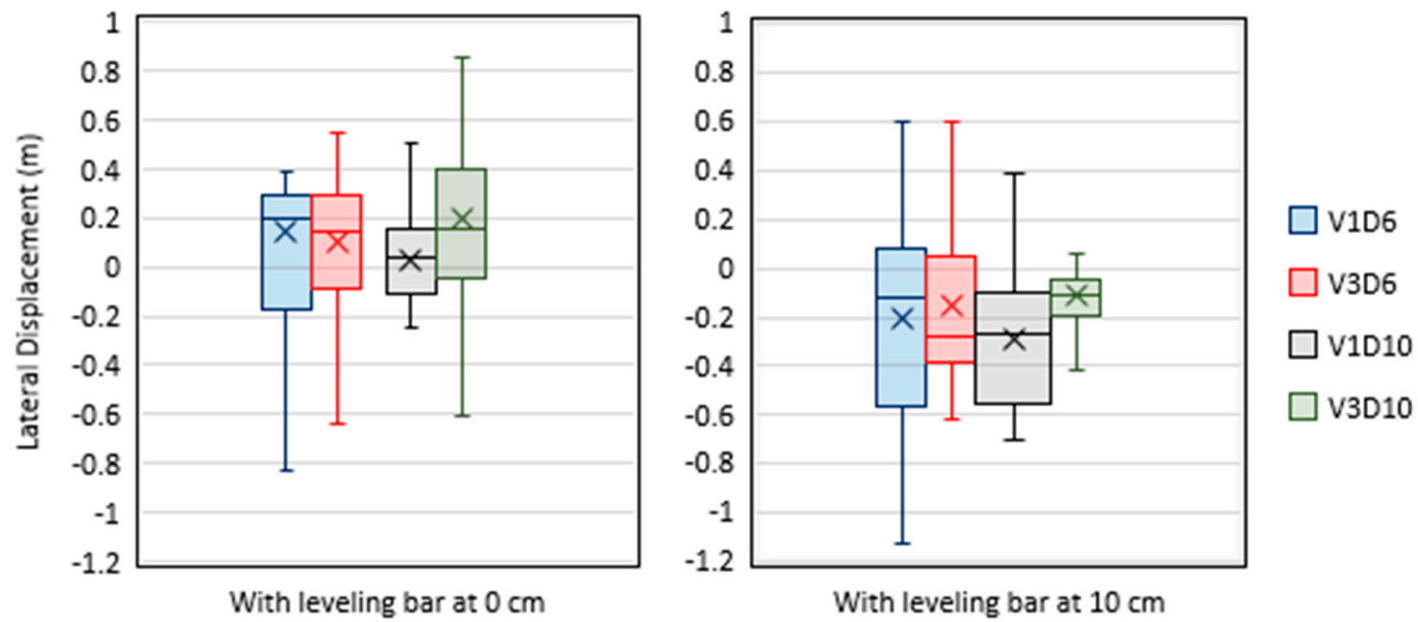

Figure 6. Average trackers lateral movement at different working conditions.
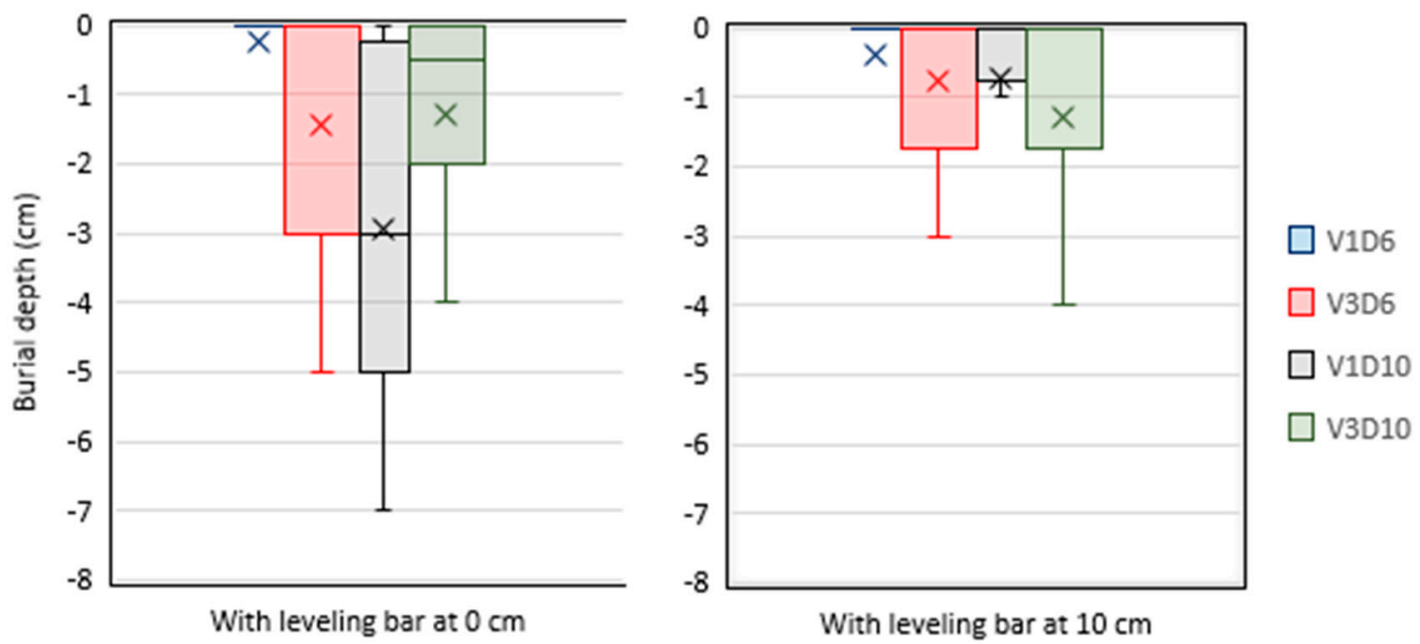

Figure 7. Average trackers burial depth at different working conditions.

Moreover, $38 \%$ of trackers were covered by soil after the harrowing process. The average cover depth was ranging between $0.01 \mathrm{~m}$ and $0.07 \mathrm{~m}$. In addition, at the working depth of $0.1 \mathrm{~m}$ and levelling bar at ground level, more than $60 \%$ of trackers were covered by soil, which highlights a higher mixing rate at these conditions. Such higher mixing rate is due to the higher interaction between the soil and machine in terms of higher tines depth and longer contact compared with other studied working conditions. Also, it can be noticed how higher tillage speed resulted in higher trackers displacements, in agreement with Liu et al. [26] in sweep trials at soil bin.

The experimental results exhibited a large variability especially when the bar was set at a null height, which was the main reason for no significant differences between variables. Such large variations were due to a number of reasons such as; tracker (rigid material of cork) might be hit by 
tines and thrown at long distances, or tracker dragging through tillage operation, in agreement with similar results reported by different relevant research works in soil bin trials [26,27].

Besides characterization of the topsoil movement after the application of rotary harrow tillage operation, the proposed study demonstrates the effectiveness of the RFID technique soil movements monitoring operations. Differently, from metal or polymer trackers, RFID allows minimization of tags dimensions, allowing univocal identification and maximizing localization process both in terms of high detection percentage (close to $100 \%$, and lower in case of harsh operation possibly affecting RFID tags integrity) and low detection time (a few seconds per tag). Additionally, it is also worth noting how the RFID approach can be in principle applied in order to simulate different materials in similar trials. The very tiny shape of RFID tags offers a wide range of simulations such as soil clods, stones, and crop residues of different shapes and densities. The best simulation for any studied object is the object itself where the material properties, such as density, surface roughness, and shape, will simulate and act naturally. Figure 8 illustrates the possibility of integrating the RFID tags in wheat spikes, straw, corn residues, potato, soil clods, or even small rocks for suggested future applications. In addition, it is worth mentioning that the easy recognition of RFID by the antenna and the unique ID for each tag will reduce the source of error and limitations in open field experiments, which will also lead to more reliable and understandable results.

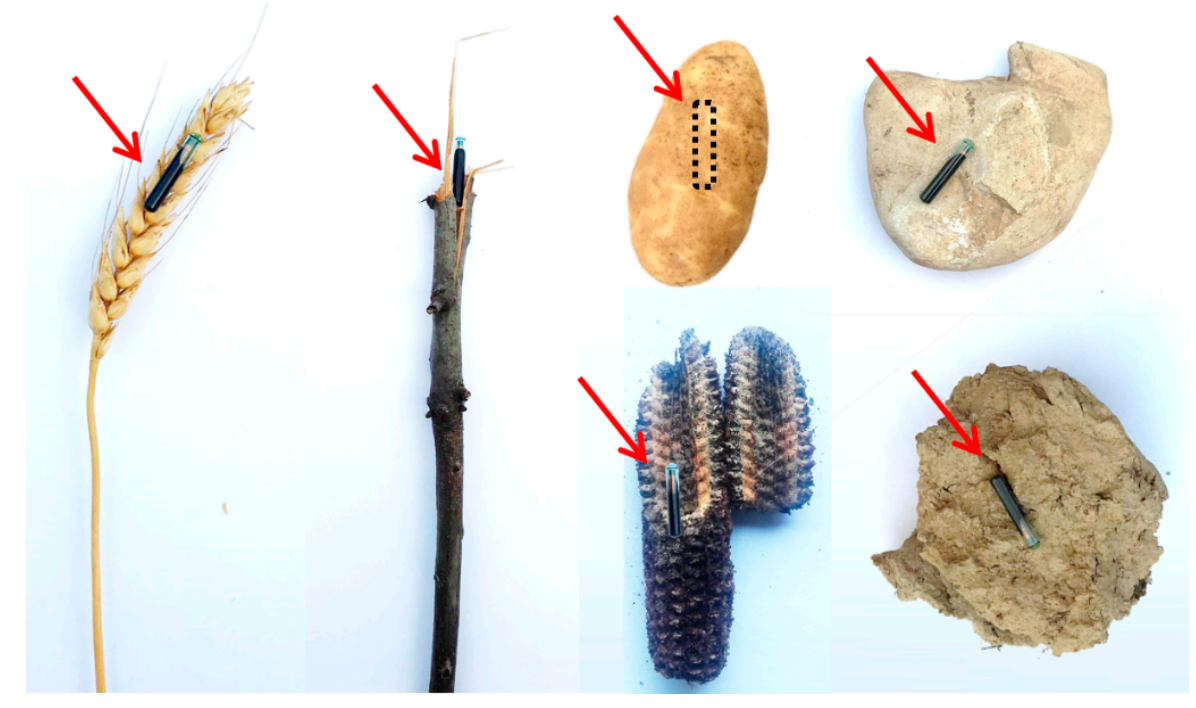

Figure 8. Suggested applications for the use of Radio-Frequency Identification (RFID) to simulate or monitor crop residues, straw, soil clods and potato in agricultural experiments.

\section{Conclusions}

Field trials were performed to investigate the effect of different rotary harrow working conditions of forward speed, levelling bar, and tillage depth on topsoil aggregates displacement using RFID technique. Results showed no significant difference between treatments, while the higher displacement was noticed from the levelling bar factor. The average movement was about $2.3 \mathrm{~m}$ in the machine direction and exceeded $5 \mathrm{~m}$ in different cases. Lateral movements were limited to $0.03 \mathrm{~m}$ on average because of the different rotating directions between each tine pairs. Also, at the levelling bar of $0.1 \mathrm{~m}$, $60 \%$ of trackers were buried because of the high mixing rate. Furthermore, using RFID tags and the antenna was a promising application in this field, since it is providing a robust way to simulate different materials.

Supplementary Materials: The following are available online at http://www.mdpi.com/2077-0472/9/8/184/s1, Supplementary Materials S1: Field trial. 
Author Contributions: Conceptualization and data analysis F.M. and A.K.; Technical, practical support and method optimization for RFID trackers R.R. and L.P.; Writing and reviewing A.K. and F.M.; Supervision L.S. and F.M.

Funding: This research was financially supported by the CARIPARO foundation (AGRIGNSSVeneto-Precision positioning for precision agriculture project), University of Padova research projects (BIRD167919-Sediment transfer processes in an Alpine basin: Sediment cascades from hillslopes to the channel network) and (BIRD185008-Sediment dynamics in alpine environment: analysis of sediment mobility, propagation velocity and bedload magnitude in high gradient streams).

Acknowledgments: The authors acknowledge researchers involved in the project PRIN 2015 2015KTY5NW for their support in connection with the development of the technique and with the experiment.

Conflicts of Interest: The authors declare no conflict of interest.

\section{References}

1. Torabian, S.; Farhangi-Abriz, S.; Denton, M.D. Do tillage systems influence nitrogen fixation in legumes? A review. Soil Tillage Res. 2019, 185, 113-121. [CrossRef]

2. Zeyada, A.M.; Al-Gaadi, K.A.; Tola, E.; Madugundu, R.; Kayad, A.G. Impact of soil firmness and tillage depth on irrigated maize silage performance. Appl. Eng. Agric. 2017, 33, 491-498. [CrossRef]

3. Pezzuolo, A.; Dumont, B.; Sartori, L.; Marinello, F.; de Antoni Migliorati, M.; Basso, B. Evaluating the impact of soil conservation measures on soil organic carbon at the farm scale. Comput. Electron. Agric. 2017, 135, 175-182. [CrossRef]

4. Van Muysen, W.; Govers, G. Soil displacement and tillage erosion during secondary tillage operations: The case of rotary harrow and seeding equipment. Soil Tillage Res. 2002, 65, 185-191. [CrossRef]

5. Cherubini, F.; Ulgiati, S. Crop residues as raw materials for biorefinery systems-A LCA case study. Appl. Energy 2010, 87, 47-57. [CrossRef]

6. Graham, R.L.; Nelson, R.; Sheehan, J.; Perlack, R.D.; Wright, L.L. Current and potential U.S. corn stover supplies. Agron. J. 2007, 99, 1-11. [CrossRef]

7. Cillis, D.; Maestrini, B.; Pezzuolo, A.; Marinello, F.; Sartori, L. Modeling soil organic carbon and carbon dioxide emissions in different tillage systems supported by precision agriculture technologies under current climatic conditions. Soil Tillage Res. 2018, 183, 51-59. [CrossRef]

8. Pezzuolo, A.; Basso, B.; Marinello, F.; Sartori, L. Using SALUS model for medium and long term simulations of energy efficiency in different tillage systems. Appl. Math. Sci. 2014, 8, 129-132. [CrossRef]

9. Chen, Y.; Monero, F.V.; Lobb, D.; Tessier, S.; Cavers, C. Effects of six tillage methods on residue incorporation and crop performance in a heavy clay soil. Trans. ASAE 2004, 47, 1003-1010. [CrossRef]

10. Wagner, L.E.; Nelson, R.G. Mass reduction of standing and flat crop residues by selected tillage implements. Trans. ASAE 1995, 38, 419-427. [CrossRef]

11. Dubbini, M.; Pezzuolo, A.; de Giglio, M.; Gattelli, M.; Curzio, L.; Covi, D.; Yezekyan, T.; Marinello, F. Last generation instrument for agriculture multispectral data collection. CIGR J. 2017, 19, 158-163.

12. Lindstrom, M.J.; Nelson, W.W.; Schumacher, T.E.; Lemme, G.D. Soil movement by tillage as affected by slope. Soil Tillage Res. 1990, 17, 255-264. [CrossRef]

13. Thapa, B.B.; Cassel, D.K.; Garrity, D.P. Assessment of tillage erosion rates on steepland Oxisols in the humid tropics using granite rocks. Soil Tillage Res. 1999, 51, 233-243. [CrossRef]

14. Marshall, E.J.P.; Brain, P. The horizontal movement of seeds in arable soil by different soil cultivation methods. J. Appl. Ecol. 1999, 36, 443-454. [CrossRef]

15. Kaur, M.; Sandhu, M.; Mohan, N.; Sandhu, P.S. Technology principles, advantages, limitations and its applications. Int. J. Comput. Electr. Eng. 2011, 3, 1793-8163. [CrossRef]

16. Want, R. An introduction to RFID technology. IEEE Pervasive Comput. 2006, 5, 25-33. [CrossRef]

17. Nikitin, P.V.; Rao, K.V.S. Theory and measurement of backscattering from RFID tags. IEEE Antennas Propag. Mag. 2006, 48, 212-218. [CrossRef]

18. Tian, F. An agri-food supply chain traceability system for China based on RFID \& blockchain technology. In Proceedings of the 13th International Conference on Service Systems and Service Management (ICSSSM), Kunming, China, 24-26 June 2016.

19. Vanderroost, M.; Ragaert, P.; Devlieghere, F.; de Meulenaer, B. Intelligent food packaging: The next generation. Trends Food Sci. Technol. 2014, 39, 47-62. [CrossRef] 
20. Prinsloo, J.; Malekian, R. Accurate vehicle location system using RFID, an internet of things approach. Sensors 2016, 16, 825. [CrossRef]

21. Abdullah, M.F.F.; Ali, M.T.B.; Yusof, F.Z.M. Rfid application development for a livestock monitoring system. In Bioresources Technology in Sustainable Agriculture; Apple Academic Press: Palm Bay, FL, USA, 2018; pp. 103-116.

22. Parsons, A.; Cooper, J.; Onda, Y.; Sakai, N. Application of RFID to soil-erosion research. Appl. Sci. 2018, 8, 2511. [CrossRef]

23. Rainato, R.; Mao, L.; Picco, L. Near-bankfull floods in an Alpine stream: Effects on the sediment mobility and bedload magnitude. Int. J. Sediment. Res. 2018, 33, 27-34. [CrossRef]

24. Picco, L.; Tonon, A.; Rainato, R.; Lenzi, M.A. Bank erosion and large wood recruitment along a gravel bed river. J. Agric. Eng. 2016, 47, 72. [CrossRef]

25. Le Breton, M.; Baillet, L.; Larose, E.; Rey, E.; Benech, P.; Jongmans, D.; Guyoton, F.; Jaboyedoff, M. Passive radio-frequency identification ranging, a dense and weather-robust technique for landslide displacement monitoring. Eng. Geol. 2019, 250, 1-10. [CrossRef]

26. Liu, J.; Chen, Y.; Kushwaha, R.L. Effect of tillage speed and straw length on soil and straw movement by a sweep. Soil Tillage Res. 2010, 109, 9-17. [CrossRef]

27. Liu, J.; Chen, Y.; Lobb, D.A.; Kushwaha, R.L. Soil-straw-tillage tool interaction: Field and soil bin study. Can. Biosyst. Eng. Genie Biosyst. Can. 2007, 49, 2.

(C) 2019 by the authors. Licensee MDPI, Basel, Switzerland. This article is an open access article distributed under the terms and conditions of the Creative Commons Attribution (CC BY) license (http://creativecommons.org/licenses/by/4.0/). 